\title{
Immunohistochemical Aspects of Ito and Kupffer Cells in the Liver of Domesticated and Wild Ruminants
}

\author{
Valentina Carollo, Alessia Di Giancamillo, Francesca Vitari, Rainer Schneider, \\ Cinzia Domeneghini* \\ Department of Health, Animal Science and Food Safety, Università degli Studi di Milano, Milan, Italy \\ Veterinary Practitioner, "Le Cornelle" Parco Faunistico, Bergamo, Italy \\ Email: "cinzia.domeneghini@unimi.it, tapirovet@libero.it, valentina.carollo@unimi.it, alessia.digiancamillo@unimi.it, \\ francesca.vitari@unimi.it
}

Received July 4, 2012; revised July 31, 2012; accepted August 7, 2012

\begin{abstract}
The mammalian liver is a morphologically and functionally complex organ, made up of not only of the largely predominant parenchymal cells (hepatocytes) but also non-parenchymal cells. Although there are less non-parenchymal cells than hepatocytes, they nevertheless play an important role in regulating many hepatocyte functions, as well as in the immunology of the liver. We investigated the structural aspects of the liver and the morpho-functional characteristics of Ito and Kupffer cells in two domesticated ruminant species (cattle and goat) in comparison with four wild ruminant species living in captivity in a zoo in northern Italy. The liver specimens were studied using histological, histochemical and immunohistochemical methods. The liver parenchyma was structurally normal. Immunohistochemistry was performed for desmin, glial fibrillary acidic protein (GFAP), vimentin, $\alpha$-smooth muscle actin ( $\alpha$-SMA), collagen I, lysozyme, CD 68 and tumor necrosis factor $\alpha$ (TNF- $\alpha$ ). In all the studied ruminants, Ito cells reacted with desmin and vimentin antibodies, Kupffer cells were evidenced only with lysozyme-immunopositivity, and both displayed a characteristic distribution in the hepatic lobular/acinar structure. The results obtained, not only contribute to the knowledge of ruminant wild species, but also help to define a normal structure reference for the diagnosis and treatment of liver diseases.
\end{abstract}

Keywords: Liver Non-Parenchymal Cells; Captive Wild Ruminants; Histology; Histochemistry

\section{Introduction}

The mammalian liver is a morphologically and functionally complex organ, made up not only of the largely predominant parenchymal cells (hepatocytes), but also non-parenchymal cells (N-PCs), including Ito, Kupffer and sinusoidal endothelial cells (SECs), as well as other cell types that reside in the sinusoidal compartment [1-3]. Although present in a small percentage in the total liver volume (around 6\%), non-parenchymal cells play an important role in the regulation of many hepatocyte functions $[1,4]$ as well as in the immunobiology of the liver [5], in both normal and pathological conditions [6]. Hepatic stellate cells (HSCs) also called Ito cells, fat-storing cells, lipocytes [7], are vitamin A-storing cells located in the space of Disse between hepatocytes and sinusoidal endothelial cells, which is why they are also called perisinusoidal cells. These cells constitute approximately $5 \%$ of the total number of liver cells [2], their cytoplasm is especially rich in lipid droplets (long-chain fatty acid

${ }^{*}$ Corresponding author. esters of retinal, retinyl palmitate), and show long, branched cytoplasmic processes that embrace the endothelial cells $[1,8]$. In addition they are able to modulate the turnover of parenchymal cells and regulate liver regeneration. Owing to their smooth muscle $\alpha$-actin when contracting, these NPCs may reduce the lumen of sinusoid capillaries, in such a way modulating the liver sinusoidal blood flow. When the liver is damaged, the hepatic stellate cells change their shape and transform (via a process named "activation") into the myofibroblast-like cells, which are the major cell type responsible for the onset of liver inflammatory fibrosis and eventually cirrhosis [9]. Myofibroblast-like cells are highly proliferating and secrete a large quantity of extracellular matrix proteins (collagens type I and III, proteoglycan, adhesive glycoproteins), as well as extra-cellular matrix degrading metalloproteinases, cytokines and chemokines, but lose their function with regard to the vitamin A metabolism [10]. They promote hepatic fibrogenesis, possibly together with portal fibroblasts and parenchymal cells, and parenchymal cells in parallel begin to be transformed 
into mesenchymal cells (epithelial to mesenchymal transition) [11]. Kupffer cells are the liver resident macrophages. They are intrasinusoidal and display huge endocytic and non specific phagocytic activities, since they are a part of the reticulo-endothelial system. The liver contains one of the largest resident populations of macrophages [12], which are key components of the innate immune system [13] and derive from circulating monocytes [2]. Kupffer cells represent approximately $30 \%$ of NPC fractions and approximately $15 \%$ of all liver cells [2]. The distribution of Kupffer cells within the hepatic lobules/acini is variable and perhaps speciesspecific: in the rat, the periportal area contains $43 \%$ of the cells, the midzonal region approximately $28 \%$ and the remaining $29 \%$ of Kupffer cells are located in the centre of the hepatic lobules/acini [14]. They remove senescent and damaged erythrocytes from circulation, which may lead to an excess of cellular iron deposits in some storage diseases, as the effect of either seasonal variations or metabolic dysregulation phenomena $[15,16]$. Kupffer cells phagocyte the great majority of bacterial products coming from the gut, and consequently are responsible for the onset of the acute phase response and produce a large variety of inflammatory mediators (IL-1, TNF- $\alpha$, TGF- $\beta$ ), which in turn may induce liver injury. As a response to inflammatory inputs, Kupffer cells (and in some species, also Ito cells) release prostaglandins from arachidonic acid via cyclooxigenases (COX)-1, -2. Prostaglandins affect the hepatic glucose and lipid metabolisms [17], and elicit oxidative stress molecules that are read by hepatocytes as apoptogenic stimuli. They have a limited local proliferating ability and, together with SECs, express scavenger, mannose, and membrane receptors for the $\mathrm{Fc}$ region of $\mathrm{IgG}$ and for the complement $[2,6]$. In summary, both Ito and Kupffer cells share a fundamental role in the occurrence of some pathological liver conditions, however, paradoxically, the histochemical and immunohistochemical aspects of both these cell types are better known in terms of their relationship to pathological rather than normal conditions. Thus, also bearing in mind the complex heterogeneity (sometimes species-specific) of these non parenchymal cells, our aim was to investigate the structural aspects of the liver, and to detail the morpho-functional characteristics of Ito and Kupffer cells in two domesticated ruminant species (cattle, goat: browsers) in comparison with wild ruminant species (grazers and foliage selectors) living in captivity at a zoo in northern Italy. In addition the aim was to identify the fundamentals of the normal liver structure in mammals that to date have not been fully investigated, in order to improve the present structural framework, to which one can refer for describing possible hepatic diseases. This might then lead to a better quality of care and management of zoo animals, where captivity is fundamental for safeguarding endangered species, but which can also involve stressful environmental conditions.

\section{Materials and Methods}

\subsection{Animals and Tissues Processing}

Approximately $1 \mathrm{~cm}^{3}$ of liver samples (similar lobes) from different ruminant species (two adult individuals for each species) were collected, promptly after death: Holstein Freisian cattle (Bos taurus) and Saanen goat (Capra hircus) livers were obtained at slaughter; giraffe (Giraffa camelopardalis), reindeer (Rangifer tarandus), scimitar oryx (Oryx dammah) and Mrs Gray's lechwe (Kobus megaceros) livers were obtained during necropsies, which were performed on the animals in 2010-2011 years at "Le Cornelle" park in the north of Italy. The captive wild ruminants live in mono-specific large enclosures planned to recreate conditions similar to wildlife. The diet of these captive wild ruminants is the same, and is composed by barley, bran, pellet and some seasonal fruit and vegetables. Only giraffe meal is enriched with maize and carob and with acacia apical branches sup- plied with high mangers. These captive wild ruminants had died for reasons unrelated to gastrointestinal diseases: these varied from traumatic lesions from conspecific to post-partum complications as well as to heart dysfunction. The gross anatomy of the livers was in all cases judged to be normal. The hepatic liver samples were fixed by immersion in $10 \%$ neutral-buffered formalin, routinely embedded in paraffin, and then sectioned $4 \mu \mathrm{m}$ thick. The paraffin sections, after dewaxing and rehydration, were treated with histological, histochemical and immunohistochemical stains, as described below.

\subsection{Histological and Histochemical Analyses}

Dewaxed sections were stained with Haematoxylin and Eosin (HE) sequential stain, Masson's trichromic stain, and Gordon and Sweet's modified procedure for reticulum [18], the latter for revealing the liver architecture.

\subsection{Immunohistochemical Analyses}

After dewaxing and endogenous peroxidase blocking with $\mathrm{H}_{2} \mathrm{O}_{2}, 10 \%$ for 10 minutes, slides were pre-treated with either a microwave treatment (twice for 5 minutes at $450 \mathrm{~W}$ in a citrate buffer $\mathrm{pH} 6$, with a 20 minute interval between the two treatments; Table 1) or proteinase K $(0.2 \%$ proteinase $\mathrm{K}$ in $\mathrm{PBS} \mathrm{pH} 7.4$ at room temperature for 5 minutes; Table 1) to induce antigen retrieval. Sections were then incubated overnight at room temperature in a humid chamber with the primary antibodies (see Table 1). Sections were subsequently incubated with EnVision ${ }^{\mathrm{TM}}$ Detection Systems, Rabbit or Mouse (Dako- 
cytomation, Italy) and the reaction products were visualized with a freshly prepared solution of 3.3-diaminobenzidine tetrahydrochloride (DAB, Sigma, Italy), $10 \mathrm{mg}$ in $15 \mathrm{ml}$ of a $0.5 \mathrm{M}$ Tris buffer at $\mathrm{pH} 7.6$, containing 1.5 $\mathrm{ml}$ of $0.03 \% \mathrm{H}_{2} \mathrm{O}_{2}$. To ascertain structural details, sections were slightly counterstained with Mayer's haematoxylin. Porcine liver sections were used as a positive control. For the negative controls, other sections were processed simultaneously with the procedure described above, except that the primary antibodies were substituted with 1 (PBS, 2) preimmune sera. Both these procedures gave negative results.

\section{Results}

\subsection{Histological and Histochemical Analyses}

The histological and histochemical observations confirmed the observations following gross anatomy examination: The liver parenchyma was structurally normal, the central vein and the portal spaces were always evident, and the connective component that accompanies the lobular structure was rather scarce (Figures 1(a) and (b)).

Masson's trichromic stain showed that in the cattle, goat and reindeer livers, the connective tissue was present small quantities in the capsule, portal areas, and delineating the lobular septae (Figure 2(a)). In the giraffe, scimitar oryx and Mrs Gray's lechwe livers, the portal areas were more clearly characterized by the presence of connective tissue (Figure 2(b)).

The histochemical stain aimed at highlighting the reticular fibres that support the hepatic parenchyma also showed the normal architecture of the lobular structure (Figures 3(a) and (b)).

\subsection{Immunohistochemical Analyses}

Immunohistochemistry was used to demonstrate the presence of Ito and Kupffer cells (see Table 2).

Table 1. Primary antisera used, aimed at identifying Ito and Kupffer cells (overnight at room temperature for all of them; PK = Proteinase K).

\begin{tabular}{ccccc}
\hline & Code & Source & Dilution & $\begin{array}{c}\text { Antigen } \\
\text { retrieval }\end{array}$ \\
\hline CD 68 & H7122 & Dakocytomation & $1: 50$ & Heat \\
Collagen I & 7066 & Chondrex & $1: 400$ & Heat \\
Desmin & H7094 & Dakocytomation & $1: 50$ & Heat \\
GFAP & 20334 & Dakocytomation & $1: 500$ & PK \\
Lysozyme & A0099 & Dakocytomation & $1: 400$ & PK \\
$\alpha$-SMA & H7114 & Dakocytomation & $1: 50$ & Heat \\
TNF- $\alpha$ & Ab6671 & Abcam & $1: 100$ & Heat \\
Vimentin & $674 M$ & Biogenex & $1: 10$ & Heat \\
\hline
\end{tabular}

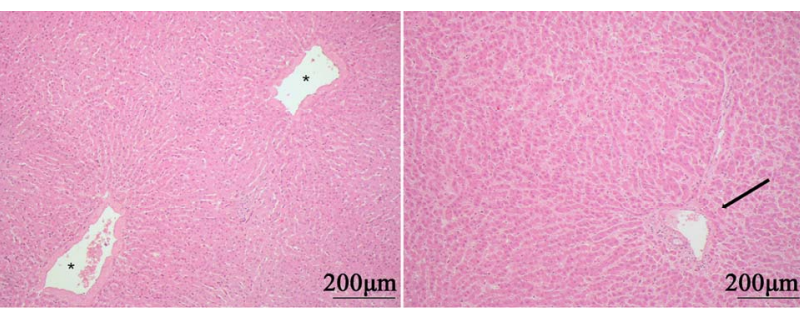

(a)

(b)

Figure 1. Ruminant livers. HE sequential stain. (a) Giraffe: the liver structure is normal. Two central veins (asterisks) are visible. Scale bar $200 \mu \mathrm{m}$; (b) Reindeer: the hepatic parenchyma is normal. A portal area is present (arrow). Scale bar $200 \mu \mathrm{m}$.

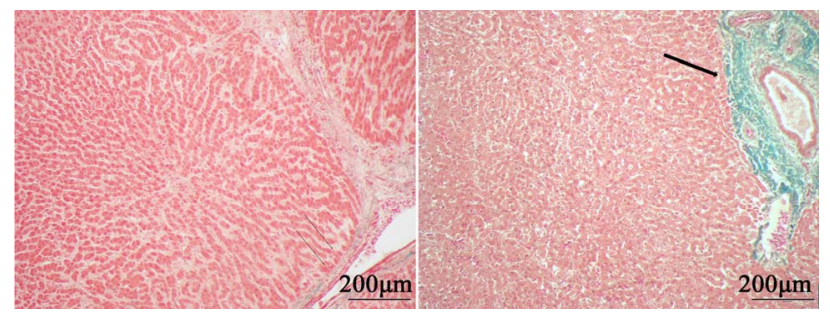

(a)

(b)

Figure 2. Ruminant livers. Masson's trichromic stain. (a) Reindeer: the connective tissue component is very scarce (thin arrows). Scale bar $200 \mu \mathrm{m}$; (b) Scimitar oryx: the connective tissue is relatively abundant in a portal area (arrow). Scale bar $200 \mu \mathrm{m}$.

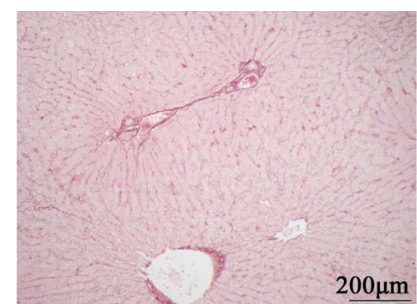

(a)

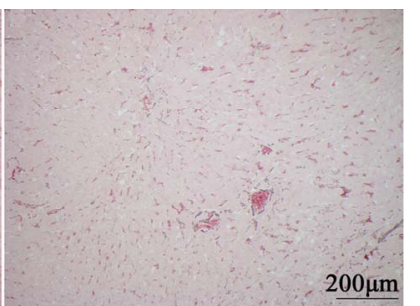

(b)
Figure 3. Ruminant livers. Gordon and Sweets' modified method for reticulum. (a) Cattle; (b) Scimitar oryx: the normal architecture of the liver is demonstrated by the reticular fibers running. Scale bar $200 \mu \mathrm{m}$.

None cell type was revealed by applying anti- $\alpha$-SMA and anti-Collagen I antibodies (data not shown), whereas anti-GFAP immunohistochemistry showed small, roundish to irregular perisinusoidal cells in the cattle and reindeer livers (Figure 4).

In addition, a number of similar, variously sized, perisinusoidal cells were found to be immunopositive to both anti-desmin (Figure 5) and anti-vimentin (Figure 6) antibodies in all the animals. In the bovine, goat and oryx livers these desmin (Figure 5(a)) and vimentin (Figure 6(a)) immunopositive cells were prevalently roundish, and contained cytoplasmic vacuoles that appeared to be devoid of contents after the applied routine procedure for 
paraffin embedding, and were thus interpreted as rich in lipid content. Giraffe, reindeer and Mrs Gray's lechwe presented another immunohistochemical feature: Desmin (Figure 5(b)) and vimentin (Figure 6(b)) immunopositive cells predominantly exhibited a stellate shape with extensive long cytoplasmic processes running along or encircling the sinusoids. In the latter animals, roundish desmin and vimentin-immunopositive cells were also present, however in fewer numbers than the immunopositive stellate cells.

The distribution of this type of perisinusoidal cells was different in the animals studied: in the cattle, giraffe (Figure 7(a)) and scimitar oryx, desmin and vimentinimmunopositive cells were more numerous in the pericentral than the periportal areas of the hepatic lobules. In contrast in the goat (Figure 7(b)), reindeer and Mrs Gray's lechwe, these cells were more numerous in the periportal areas.

One other non-parenchymal cell type was immunohistochemically found in all the studied ruminants, with a characteristic localization (in the sinusoid wall), and

Table 2. Ito and Kupffer cells immunoreactivities in the six ruminant species.

\begin{tabular}{ccccccccc}
\hline & & Ca & Go & Gi & Re & SO & MGL \\
\hline & $\alpha$-SMA & - & - & - & - & - & - \\
Collagen I & - & - & - & - & - & - \\
Ito cells & GFAP & + & - & - & + & - & - \\
& Desmin & + & + & + & + & + & + \\
& Vimentin & + & + & + & + & + & + \\
\hline \multirow{2}{*}{$\begin{array}{c}\text { Kupffer } \\
\text { cells }\end{array}$} & Lysozyme & + & + & + & + & + & $+/-$ \\
& TNF- $\alpha$ & - & - & - & + & - & - \\
\hline
\end{tabular}

$\mathrm{Ca}=$ cattle; $\mathrm{Go}=$ goat; $\mathrm{Gi}=$ giraffe $; \mathrm{Re}=$ reindeer; $\mathrm{SO}=$ scimitar oryx; MGL $=$ MRs Gray's lechwe

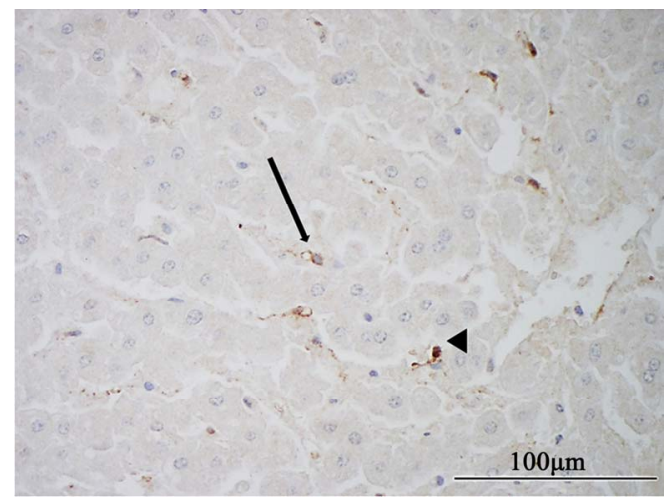

Figure 4. Ruminant liver. GFAP-immunohistochemistry. Reindeer: small, roundish (arrow) to irregular (arrowhead) immunopositive cells are visible in perisinusoidal localizations. Scale bar $100 \mu \mathrm{m}$.

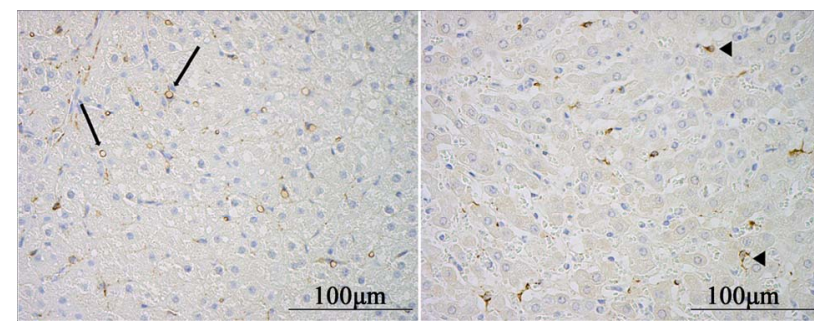

Figure 5. Ruminant livers. Desmin-immunohistochemistry. (a) Goat: several small roundish (arrows) immunopositive cells are visible in perisinusoidal areas. The cytoplasm clearly shows a lipid content. Scale bar $100 \mu \mathrm{m}$; (b) Giraffe: numerous irregularly shaped immunopositive cells are present in perisinusoidal localizations (arrowheads). Scale bar $100 \mu \mathrm{m}$.

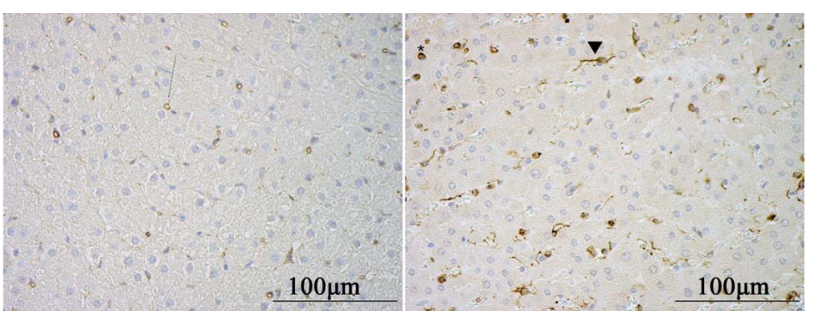

Figure 6. Ruminant livers. Vimentin immunohistochemistry. (a) Goat: small roundish (thin arrow) immunopositive cells are visible in perisinusoidal areas. The cytoplasm clearly shows a lipid content. Scale bar $100 \mu \mathrm{m}$; (b) Giraffe: numerous irregularly shaped immunopositive cells are present in perisinusoidal localizations (arrowhead). A smaller number of roundish immunopositive cells are also present (asterisk). Scale bar $100 \mu \mathrm{m}$.

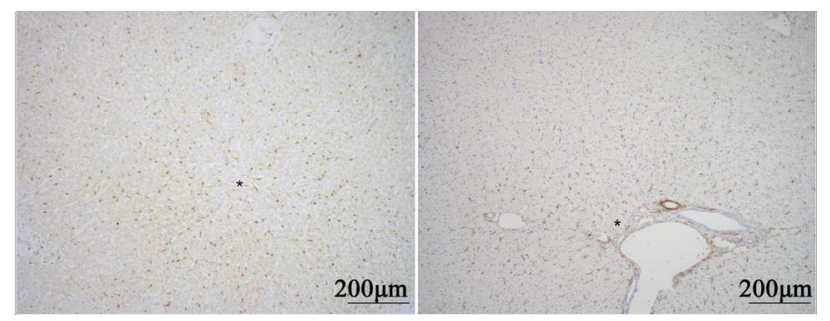

Figure 7. Ruminant livers. Desmin immunohistochemistry. (a) Giraffe: Immunopositivity is mainly visible in a pericentral area (asterisk). Scale bar $200 \mu \mathrm{m}$; (b) Goat: the immunopositivity is mainly visible in a periportal area (asterisk). Scale bar $200 \mu \mathrm{m}$.

shape (irregular or spindled): this cell type was lysozyme-immunopositive (Figure 8), although the intensity of the immunoreactions was not the same for all the animals studied, and was particularly scarce in Mrs Gray's lechwe. These non-parenchymal cells were more numerous in the periportal (Figure 8) than the pericentral areas, and this distribution was uniformly observed in the liver of all the animals studied.

This cell type was also TNF- $\alpha$-immunopositive, but limited to reindeer liver, and was not immunopositive to the CD 68 anti-body (data not shown). 


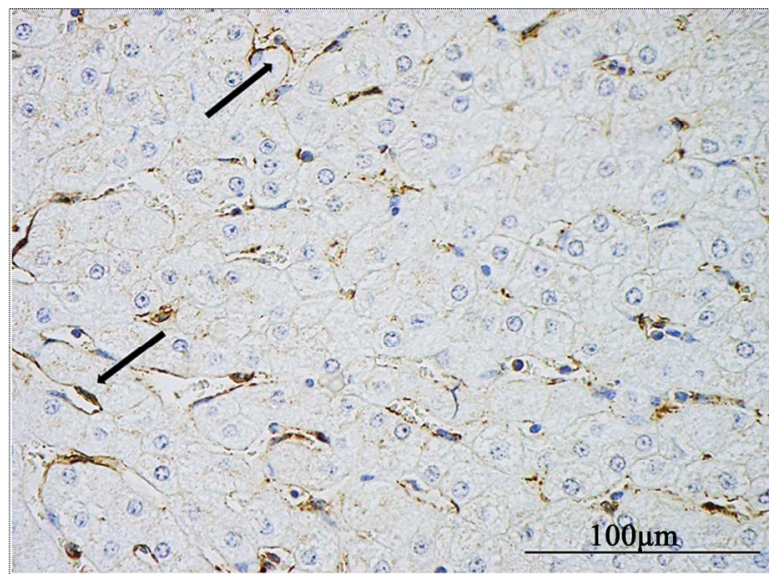

Figure 8. Ruminant liver. Lysozyme-immunohistochemistry. Cattle: numerous immunopositive, irregularly shaped cells are visible in the sinusoid walls (arrows). Scale bar 100 $\mu \mathrm{m}$.

\section{Discussion}

In this study we examined the liver of six different ruminants belonging to the Artiodactyla order. Judging from the histology and histochemistry, the architecture of the liver of these ruminants was normal. Its structure corresponded to what is known for ruminant species, especially concerning the generally limited quantity of connective tissue in the normal hepatic lobular/acinar structure. Considering the mutual relationship of the nonparenchymal cells in developing hepatic diseases, special attention was paid to the immunohistochemical features of the Ito and Kupffer cells that were revealed by panels of immunohistochemical markers. In all the ruminant species analyzed in this study, the variously sized and shaped Ito cells, with their characteristic content of cytoplasmic fat droplets, showed a positive reactivity to anti-desmin and anti-vimentin antibodies, as also observed by Neubauer et al. [19] and Uetsuka et al. [20]. In the case of the cattle and reindeer, Ito cells were also immunopositive for GFAP, in accordance with Neubauer et al. [19], who identified this marker in the rat liver and in vitro experiments. In humans hepatic stellate cells are also detectable using GFAP-immunopositivity, however the intensity of the reaction increases when fibrosis develops [21]. Cattle, goat and scimitar oryx livers showed rounded lipid vacuoles in the cytoplasm of Ito cells, which were more abundant in the pericentral area. Giraffe, reindeer and Mrs Gray's lechwe liver Ito cells exhibited a stellate shape with extensive long cytoplasmic processes running along or encircling sinusoids, and were more evident in the periportal area. No positive immunostaining for $\alpha$-SMA was observed in the Ito cells, which is in line with Uetsuka's study on bovine liver [20]. The absence of immunopositivity for both $\alpha$-SMA and Collagen I is likely due to the absence of Ito cell active- tion, that is, Ito cells were not transforming into myofibroblast-like cells. Accordingly, the liver in all the ruminants of this study appeared to be fully normal and did not display fibrosis. Liver fibrosis has been described in ruminant species, above all in cattle [22-24], in which, as in other mammals, this disease represents the liver's response, via the activation of stellate cells, to inflamematory, toxic, infectious or metabolic stimuli $[25,26]$. Kupffer cells are fundamental in sustaining the immunobiology of the liver both in normal and pathological conditions. They are also able to modulate systemic immune tolerance, via their capacity to suppress $T$ cell activation $[6,27]$. Together with Ito cells, the liver resident macrophages contribute to an assessment of liver fibrosis [28]. Ruminant Kupffer cells showed a clear lysozyme-immunoreactivity; only in Mrs Gray's lechwe's did they present a scarce immunopositivity to lysozyme. In the reindeer, Kupffer cells were also immunopositive for TNF- $\alpha$. Kushibishi [29] demonstrated in cattle that TNF$\alpha$ from activated Kupffer cells regulates inflammatory responses in mastitis, and affects metabolic disorders, such as acidosis. None of the ruminants livers showed an immunoreactivity to $\mathrm{CD} 68$, in contrast with other studies on different mammals $[28,30]$. This apparent immunohistochemical heterogeneity was expected, because it is well known that macrophages are differently detected in their various tissue localizations and species [31,32]. Ruminant Kupffer cells were located in the sinusoid walls, showed an irregular shape, and were more numerous in the periportal than the pericentral areas, in accordance with studies in other mammals [33]. When the liver is injured, Kupffer cells activate and contribute to the immune cell responses [34-36]. Kupffer cells have been shown to contain $\operatorname{PrP}(\mathrm{Sc})$ (a marker of prion disease) in experimentally infected sheep [35], and, when activated, may release a lot of inflammatory mediators in cattle [37]. Ruminant Kupffer cells are evidently damaged in intoxication phenomena, which sometimes give rise to lysosomal storage diseases [38,39], and poisoning $[40,41]$. To the best of our knowledge, this is the first description of the morphofunctional aspects and distribution of non-parenchymal cell types in wild ruminants. Since Sleyster and Knook's study on the rat [42], it has been well known that functional gradients exist in the lobular distributions of liver nonparenchymal cells, in particular of Kupffer cells, and these functional distributing differences may potentially help in elucidating pathogenic mechanisms [2]. In conclusion, we have shown the immunohistochemical features and morphological distribution of Kupffer and Ito cells in the liver of six different ruminant species. Four of these species were originally wild ruminants kept in a zoo in northern Italy. The examined ruminants belonged to three different feeding habits (sometimes overlapping), according to the 
classification by Hofmann and Stewart [43], updated by Hackmann and Spain [44]: reindeer, scimitar oryx and Mrs Gray's lechwe are grass and roughage eaters (grazers), the giraffe is a concentrate herbage and foliage selector, and cattle and goat are intermediate feeders (browsers). This classification, which above all concerns the morphology and morphometry of the gastrointestinal tract, does not seem to affect the liver parenchyma, whose normal structure is fundamentally similar in the six examined species. The non-parenchymal cells were well evidenced by immunohistochemistry, although with some differences possibly linked to either genetics or feeding habits/plans, which need further research. Ito cells were revealed with both desmin and vimentin immunohistochemistry, Kupffer cells were immunopositive to lysozyme, and both displayed a characteristic distribution in the hepatic lobular/acinar structure. We believe that our data contribute to the knowledge of wild species, and also help to define a normal liver structure reference for the diagnosis and treatment of liver diseases.

\section{Acknowledgements}

The Authors are greatly indebted with Mister Paolo Stortini for is valuable technical support, and with "Le Cornelle" park direction for kindly providing facilities.

\section{REFERENCES}

[1] Z. Kmieć, "Cooperation of Liver Cells in Health and Disease," Advances in Anatomy, Embryology and Cell Biology, Vol. 161, No. 1, 2001, pp. 1-151.

[2] D. E. Malarkey, K. Johnson, L. Ryan, G. Boorman and R. R. Maronpot, "New Insights into Functional Aspects of Liver Morphology," Toxicologic Pathology, Vol. 33, No. 1, 2005, pp. 27-34. doi:10.1080/01926230590881826

[3] K. Uetsuka, S. Nishikawa, A. Yasoshima, H. Nakayama and K. Doi, "Histopathological Characteristics of Ito Cells and Kupffer Cells in the Feline Liver," Journal of Veterinary Medical Science, Vol. 68, No. 3, 2006, pp. 235-242. doi:10.1292/jvms.68.235

[4] A. M. Neyrinck, L. D. De Wispelaere, V. P. Vanhulle, H. S. Taper and N. M. Delzenne, "Are Kupffer Cells Involved in the Metabolic Adaptation of the Liver to Dietary Carbohydrates Given after Fasting?" Biochimica et Biophysica Acta-General Subjects, Vol. 1475, No. 3, 2000, pp. 238-244. doi:10.1016/S0304-4165(00)00070-2

[5] G. A. Parker and C. A. Picut, "Liver Immunobiology," Toxicologic Pathology, Vol. 33, No. 1, 2005, pp. 52-62. doi:10.1080/01926230590522365

[6] G. A. Parker and C. A. Picut, "Immune Functions in Nonlymphoid Organs: The Liver," Toxicology Pathology, Vol. 40, No. 2, 2011, pp. 237-247.

[7] H. Senoo, N. Kojima and M. Sato, "Vitamin A-Storing Cells (Stellate Cells)," Vitamins and Hormones, Vol. 75, 2007, pp. 131-159. doi:10.1016/S0083-6729(06)75006-3
[8] M. L. Hautekeete and A. Geerts, "The Hepatic Stellate (Ito) Cell: Its Role in Human Liver Disease," Virchows Archives, Vol. 430, No. 3, 1997, pp. 195-207. doi:10.1007/BF01324802

[9] K. Iwaisako, D. A. Brenner and T. Kisseleva, "What's New in Liver Fibrosis? The Origin of Myofibroblasts in Liver Fibrosis," Journal of Gastroenterology and Hepatology, Vol. 27, No. 2, 2012, pp. 65-68. doi:10.1111/j.1440-1746.2011.07002.x

[10] H. Senoo, K. Yoshikawa, M. Morii, M. Miura, K. Imai and Y. Meezaki, "Hepatic Stellate Cell (Vitamin A-Storing Cell) and Its Relative-Past, Present and Future," Cell Biology International, Vol. 34, No. 12, 2010, pp. 1247 1272. doi:10.1042/CBI20100321

[11] F. Tacke and R. Weiskirchen, "Update on Hepatic Stellate Cells: Pathogenic Role in Liver Fibrosis and Novel Isolation Techniques," Expert Review of Gastroenterology and Hepathology, Vol. 6, No. 1, 2012, pp. 67-80. doi:10.1586/egh.11.92

[12] M. Naito, G. Hasegawa, Y. Ebe and T. Yamamoto, "Differentiation and Function of Kupffer Cells," Medical Electron Microscopy, Vol. 37, No. 1, 2004, pp. 16-28. doi:10.1007/s00795-003-0228-x

[13] I. Kiki, B. Z. Altunkaynak, M. E. Altunkaynak, O. Vuraler, D. Unal and S. Kaplan, "Effect of High Fat Diet on the Volume of Liver and Quantitative Feature of Kupffer Cells in the Female Rat: A Stereological and U1trastructural Study," Obesity Surgery, Vol. 17, No. 10, 2007, pp. 1381-1388. doi:10.1007/s11695-007-9219-7

[14] L. Bouwens, M. Baekeland, R. De Zanger and E. Wisse, "Quantitation, Tissue Distribution and Proliferation Kinetics of Kupffer Cells in Normal Rat Liver," Hepatology, Vol. 6, No. 4, 1986, pp. 718-722. doi: $10.1002 /$ hep. 1840060430

[15] B. Borch-Iohnsen and K. Thorstensen, "Iron Distribution in the Liver and Duodenum during Seasonal Iron Overload in Svalbard Reindeer," Journal of Comparative Pathology, Vol. 141, No. 1, 2009, pp. 27-40. doi:10.1016/j.jcpa.2009.02.001

[16] P. Olias, A. T. Weiss, A. D. Gruber and R. Klopfleisch, "Iron Storage Disease in Red Deer (Cervus elaphus elaphus) Is Not Associated with Mutations in the HFE Gene," Journal of Comparative Pathology, Vol. 145, No. 2-3, 2011, pp. 207-213. doi:10.1016/j.jcpa.2010.12.012

[17] A. M. Neyrinck, S. Margagliotti, C. Gomez and N. M. Delzenne, "Kupffer Cell-Derived Prostaglandin E2 Is Involved in Regulation of Lipid Synthesis in Rat Liver Tissue," Cell Biochemistry and Function, Vol. 22, No. 5, 2004, pp. 327-332. doi:10.1002/cbf.1110

[18] H. Gordon and H. H. Sweet, "A Simple Method for the Silver Impregnation of Reticulin," American Journal of Pathology, Vol. 12, No. 4, 1936, pp. 545-552.

[19] K. Neubauer, T. Knittel, S. Aurisch, P. Fellmer and G. Ramadori, "Glial Fibrillary Acidic Protein-A Cell Type Specific Marker for Ito Cells in Vivo and in Vitro," Journal of Hepatology, Vol. 24, No. 6, 1996, pp. 719-730. doi:10.1016/S0168-8278(96)80269-8

[20] K. Uetsuka, S. Nishikawa, K. Isobe and H. Nakayama, 
"Histopathological Characteristics of Kupffer Cells and Ito Cells in the Porcine and Bovine Liver," Journal of Veterinary Medical Science, Vol. 69, No. 7, 2007, pp. 767-770. doi:10.1292/jvms.69.767

[21] S. Morini, S. Carotti, G. Carpino, A. Franchitto, S. G. Corradini, M. Merli and E. Gaudio, "GFAP Expression in the Liver as an Early Marker of Stellate Cells Activation," Italian Journal of Anatomy and Embryology, Vol. 110, No. 4, 2005, pp. 193-207.

[22] A. C. Bourque, I. C. Fuentealba, R. Bildfell, P. I. Daoust and P. Hanna, "Congenital Hepatic Fibrosis in Calves," The Canadian Veterinary Journal, Vol. 42, No. 2, 2001, pp. 145-146.

[23] M. B. Torres and K. I. Coelho, "Foamy Macrophages in the Liver of Cattle Fed Brachiaria Brizantha Hay," Veterinary and Human Toxicology, Vol. 45, No. 3, 2003, pp. 163-164.

[24] S. Haywood, T. Müller, A. M. Mackenzie, W. Müller, M. S. Tanner, P. Heinz-Erian, C. L. Williams and M. J. Loughran, "Copper-Induced Hepatotoxycosis with Hepatic Stellate Cells Activation and Severe Fibrosis in North Ronaldsay Lambs: A Model for Non-Wilsonian Hepatic Copper Toxicosis of Infants," Journal of Comparative Pathology, Vol. 130, No. 4, 2004, pp. 266-277. doi:10.1016/j.jcpa.2003.11.005

[25] K. Neubauer, B. Saile and G. Ramadori, "Liver Fibrosis and Altered Matrix Synthesis," Canadian Journal of Gastroenterology, Vol. 15, No. 3, 2001, pp. 187-193.

[26] N. R. Tomanovic, I. V. Boricic, D. C. Brasanac, Z. M. Stojsic, D. S. Delic and B. J. Brmbolic, "Activated Liver Stellate Cells in Chronic Viral C Hepatitis: Histopathological and Immunohistochemical Study," Journal of Gastrointestinal and Liver Disease, Vol. 18, No. 2, 2009, pp. 163-167.

[27] C. Ju, "The Role of Haptic Macrophages in Regulation of Idiosyncratic Drug Reactions," Toxicology Pathology, Vol. 37, No. 1, 2009, pp. 12-17. doi:10.1177/0192623308329475

[28] C. Liu, Q. Tao, M. Sun, J. Z. Wu, W. Yang, P. Jian, J. Peng, Y. Hu, C. Liu and P. Liu, "Kupffer Cells Are Associated with Apoptosis, Inflammation and Fibrotic Effects in Hepatic Fibrosis in Rats," Laboratory Investigation: A Journal of Technical Methods and Pathology, Vol. 90, No. 12, 2010, pp. 1805-1816.

[29] S. Kushibiki, "Tumor Necrosis Factor- $\alpha$-Induced Inflammatory Response in Cattle," Animal Science Journal, Vol. 82, No. 4, 2011, pp. 504-511. doi:10.1111/j.1740-0929.2011.00931.x

[30] J. H. Lefkowitch, J. H. Haythe and N. Regent, "Kupffer Cell Aggregation and Perivenular Distribution in Steatohepatitis," Modern Pathology, Vol. 15, No. 7, 2002, pp. 699-704. doi:10.1097/01.MP.0000019579.30842.96

[31] J. Yamate, H. Yoshida, Y. Tsukamoto, M. Ide, M. Kuwamura, F. Ohashi, T. Miyamoto, T. Kotani, S. Sakuma and M. Takeya, "Distributiona of Cells Immunopositive for AM-3K, a Novel Monoclonal Antibody Recognizing Human Macrophages, in Normal and Diseased Tissues of Dogs, Cats, Horse, Cattle, Pigs, and Rabbits," Veterinary
Pathology, Vol. 37, No. 2, 2000, pp. 168-176. doi:10.1354/vp.37-2-168

[32] P. Zelnickova, J. Matiasovic, B. Pavlova, H. Kudlackova, F. Kovaru and M. Faldyna, "Quantitative Nitric Oxide Production by Rat, Bovine and Porcine Macrophages," Nitric Oxide: Biology and Chemistry, Vol. 19, No. 1, 2008, pp. 36-41.

[33] P. F. Moore, "Characterization of Cytoplasmic Lysozyme Immunoreactiviry as a Histiocytic Marker in Normal Canine Tissue," Veterinary Pathology, Vol. 23, No. 6, 1986, pp. 763-769.

[34] G. L. Su, "Lipopolysaccharides in Liver Injury: Molecular Mechanisms of Kupffer Cell Activation," American Journal of Physiology. Gastrointestinal and Liver Physiology, Vol. 283, No. 2, 2002, pp. G256-G265.

[35] L. C. Kabaroff, A. Rodriguez, M. Quinton, H. Boermans and N. A. Karrow, "Assessment of the Ovine Acute Phase Response and Hepatic Gene Expression in Response to Escherichia Coli Endotoxin," Veterinary Immunology and Immunopathology, Vol. 113, No. 1-2, 2006, pp. 113-124. doi:10.1016/j.vetimm.2006.04.003

[36] S. J. Everest, A. M. Ramsay, M. J. Chaplin, S. Everitt, M. J. Stack, M. H. Neale, M. Jeffrey, S. J. Moore, S. J. Bellworthy and L. A. Terry, "Detection and Localization of Prp (Sc) in the Liver of the Sheep Infected with Scrapie and Bovine Spongiform Enecephalopathy," PLoS One, Vol. 12, No. 5, 2011, Article ID: e19737. doi:10.1371/journal.pone.0019737

[37] M. Yoshioka, T. Ito, S. Miyazaki and Y. Nakajima, "The Release of Tumor Necrosis Factor-Alpha, Interleukin-1. Interleukin-6 and Prostaglandin E2 in Bovine Kupffer Cells Stimulated with Bacterial Lipopolysaccharide," Veterinary Immunology and Immunopathology, Vol. 66, No. 3-4, 1998, pp. 301-307. doi:10.1016/S0165-2427(98)00206-2

[38] D. Driemeier, E. M. Colodei, E. J. Gimeno and S. S. Barros, "Lysosomal Storage Disease Caused by Sida Carpinifolia Poisoning in Goats," Veterinary Pathology, Vol. 37, No. 2, 2000, pp. 153-159. doi:10.1354/vp.37-2-153

[39] A. G. Armién, C. H. Tokamia, P. V. Peixoto, J. D. Barbosa and K. Frese, "Clinical and Morphological Changes in Ewes and Fetusues Poisoned by Ipomea Carnea Subspecies Fistulosa," Journal of Veterinary Diagnostic Investigation, Vol. 23, No. 2, 2011, pp. 221-232. doi: $10.1177 / 104063871102300205$

[40] M. Yamada, M. Nakagawa, M. Haritani, M. Kobayashi, H. Furuoka and T. Matsui, "Histopathological Study of Experimental Acute Poisonong of Cattle by Autumn Crocus (Colchicum Autumnale L.)," Journal of Veterinary Medical Science, Vol. 60, No. 8, 1998, pp. 949-952. doi:10.1292/jvms.60.949

[41] S. D. Stoev, N. Grozeva, R. Sieonov, I. Borisov, H. Hubenov, Y. Nikolov, M. Tsaneva and S. Lazarova, "Experimental Cadmium Poisoning in Sheep," Experimental and Toxicologic Pathology, Vol. 55, No. 4, 2003, pp. 309-314. doi:10.1078/0940-2993-00333

[42] E. C. Sleyster and D. L. Knook, "Relation between Lo- 
calization and Function of Rat Liver Kupffer Cells," Laboratory Investigation: A Journal of Technical Methods and Pathology, Vol. 47, No. 5, 1982, pp. 484-490.

[43] R. R. Hofmann and D. R. M. Stewart, "Grazer or Browser: A Classification Based on the Stomach Structure and Feeding Habits of East African Ruminants," Mammalia, Vol. 36, No. 2, 1972, pp. 226-240. doi:10.1515/mamm.1972.36.2.226

[44] T. J. Hackmann and J. N. Spain, "Invited Review: Ruminant Ecology and Evolution: Perspectives Useful to Ruminant Livestock Research and Production," Journal of Dairy Science, Vol. 93, No. 4, 2010, pp. 1320-1334. doi:10.3168/jds.2009-2071 